\title{
O SISTEMA EDUCACIONAL INTERATIVO E AS PERSPECTIVAS DE FORMAÇÃO HUMANA DOS ALUNOS DO ENSINO MÉDIO DAS COMUNIDADES RURAIS DO ESTADO DO PARÁ
}

\author{
Cleide Carvalho Matos ${ }^{1}$ \\ Manuelle Espindola dos Reis ${ }^{2}$ \\ Jeovani de Jesus Couto ${ }^{3}$
}

\begin{abstract}
RESUMO
Este artigo tem como objetivo analisar as perspectivas de formação humana presentes na proposta de educação desenvolvida por meio do Sistema Educacional Interativo no Pará. O trabalho envolveu pesquisa bibliográfica e documental. Os principais teóricos que fundamentam a análise são: Frigotto (2010a, 2010b), Saviani (2003a, 2003b, 1982), Kosik (2011), Ferreira (2015) e Angeli (2009). O Sistema Educacional Interativo, além de não potencializar a formação humana, aprofunda ainda mais as desigualdades sociais e regionais por meio de uma política educacional fragmentada e de qualidade duvidosa, pouco efetiva no desenvolvimento da formação omnilateral das populações que, historicamente, tiveram negado seu direito de acesso aos conhecimentos produzidos historicamente pela humanidade. A metodologia de ensino utilizada para ingresso no Ensino Médio pelas comunidades rurais, por meio do Sistema Educacional Interativo, pouco contribuirá para a reflexão sobre a realidade concreta desses sujeitos e, consequentemente, para sua transformação.
\end{abstract}

Palavras-chave: Sistema Educacional Interativo. Currículo. Formação humana.

\section{THE INTERACTIVE EDUCATIONAL SYSTEM AND THE PERSPECTIVES OF HUMAN TRAINING OF HIGH SCHOOL STUDENTS OF RURAL COMMUNITIES IN THE STATE OF PARÁ}

\begin{abstract}
This article aims to analyze the perspectives of human formation present in the education proposal developed through the Interactive Educational System in Pará. The work involved bibliographical and documentary research. The main theorists that support the analysis are: Frigotto (2010a, 2010b), Saviani (2003a, 2003b, 1982), Kosik (2011), Ferreira (2015) and Angeli (2009). The Interactive Educational System, in addition do not enhancing human training, further deepens social and regional inequalities through a fragmented educational policy of dubious quality, ineffective in the development of the omnilateral formation of populations that, historically, have been denied their right access to knowledge historically produced by humanity. The teaching methodology used to enter high school by rural communities, through the Interactive Educational System, will contribute a little to the reflection about the concrete reality of these subjects and, consequently, for their transformation. Keywords: Interactive Educational System. Curriculum. Human formation.
\end{abstract}

Recebido em: 30/3/2020

Aceito em: 11/5/2020

\footnotetext{
1 Autora correspondente. Universidade Federal do Pará - Campus de Breves. Av. Anajás, s/n. Aeroporto. CEP 68800-000 - Breves/PA, Brasil. http://lattes.cnpq.br/8533815869369392. https://orcid.org/0000-0003-3229-9441. cleidematos@ufpa.br

2 Secretaria Municipal de Educação de Breves. Breves/PA, Brasil. http://lattes.cnpq.br/1753345784639940.

3 Instituto Federal de Educação, Ciência e Tecnologia do Pará - Campus Breves. Breves/PA, Brasil. http://lattes.cnpq.br/9980170589567949. https://orcid.org/0000-0002-9693-1285.
} 
O Ensino Médio, etapa final da Educação Básica, vem sendo alvo de frequentes reformas, tendo sido a última expressa na Lei no 13.415, de 16 de fevereiro de 2017, que alterou a Lei 9.394/1996, provocando mudanças no currículo, na formação de professores e, consequentemente, na concepção de formação humana dos jovens do Ensino Médio.

Segundo Duarte e Derisso (2017), desde o final do século 20 o Brasil tem tentado ajustar sua política econômica e de gestão do Estado sob a orientação de organismos internacionais como o FMI, OCDE, Unesco, etc. Tais reformas vêm exigindo que a educação atenda às necessidades de mão de obra qualificada demandada pelo capital.

É atribuída à escola pública a tarefa de remodelar-se para atender às mudanças no mundo do trabalho e ao seu caráter competitivo e globalizado, impondo uma formação escolar que tenha por base o desenvolvimento de habilidades e competências ao invés do acesso ao conhecimento socialmente produzido (DUARTE; DERISSO, 2017, p. 2).

As reformas evidenciam uma concepção dualista de educação ${ }^{4}$ reforçando o compromisso com a mercantilização do ensino por meio da separação entre, de um lado, uma formação técnica e profissionalizante e, de outro, uma formação que se quer voltada ao acesso ao Ensino Superior. Na formação técnica, a dimensão da formação humana é esvaziada pela necessidade de atendimento ao mercado, às demandas do capital.

Entre os argumentos apresentados pelo Ministério da Educação para justificar a última reforma, destaca-se o baixo rendimento do Ensino Médio nas avaliações de larga escala (Pisa, Saeb e Ideb). Para Cury (1998), porém, é necessário considerar as condições em que acontece este nível de ensino: escolas com estruturas precárias, ausência de merenda escolar, falta de transporte escolar, desvalorização profissional expressa nos salários dos trabalhadores da educação. Todos esses elementos, entre outros, corroboram a precarização do Ensino Médio.

No Pará, desde a década de 80, vem ocorrendo a expansão da oferta do Ensino Médio regular na capital do Estado, adotando, como estratégia de expansão para os municípios, o Sistema de Organização Modular de Ensino (Some). ${ }^{5}$ Esta estratégia, entretanto, não tem dado conta de atender às demandas da população do interior do Estado.

Segundo o Instituto Nacional de Estudos e Pesquisas Educacionais Anísio Teixeira (Inep), a matrícula no Ensino Médio no Estado do Pará corresponde a 320.247 alunos, enquanto a matrícula no Ensino Fundamental chega a 1.314.040 (BRASIL, 2018). A Se-

\footnotetext{
Sobre este aspecto é oportuno indicar o artigo Ensino Médio: trajetória histórica e a dualidade educacional presente nas diferentes reformas, de autoria de LOPES, C. B.; BERTOLO, C. C.; ALMEIDA, S. V. Perspectiva, Florianópolis, v. 34, n. 2, p. 555-581, maio/ago. 2016. Disponível em: https://periodicos.ufsc.br/index.php/perspectiva/article/ view/2175-795X.2016v34n2p555. Acesso em: 13 maio 2020. O artigo apresenta como a dualidade educacional no Ensino Médio se materializou no conjunto de reformas educacionais inauguradas desde os anos 40 até meados dos anos 2000. A discussão aborda as principais características do sistema educacional brasileiro que historicamente reservou aos trabalhadores uma formação técnica, profissionalizante com primazia para o mercado de trabalho

5 Para uma leitura mais específica sobre o Some, ver: PEREIRA, Viviane Silva; MAULER, Celso. O sistema de organização modular de ensino: uma composição em memórias docentes. In: REUNIÃO ANUAL DA ANPED, 39., 2019. Rio de Janeiro. Anais [...]. Rio de Janeiro: UFF, 2019. Disponível em: http://39.reuniao.anped.org.br/wp-content/ uploads/sites/3/trabalhos/5626-TEXTO_PROPOSTA_COMPLETO.pdf
} 
cretaria de Estado de Educação (Seduc/PA) reconhece que não alcançou a Meta 3 do Plano Nacional de Educação (Lei n. 13.005/2014) - que trata da universalização, até 2016, do atendimento escolar a toda a população de 15 a 17 anos - bem como elevar, até o final do período de vigência deste PNE, a taxa líquida de matrículas no Ensino Médio para 85\% (BRASIL, 2014). Nesse sentido, apresentou, em 2017, o Plano de Implementação do Ensino Médio Presencial com Mediação Tecnológica denominado Sistema Educacional Interativo (SEI).

O SEI constitui em uma "[...] alternativa metodológica definitiva para atender alunos concluintes do Ensino Fundamental, das comunidades rurais nas quais não há oferta do Ensino Médio ou a demanda é superior ao número de vagas oferecidas" (PARÁ, 2017, p. 5).

Ferreira (2015) destaca que o uso de Tecnologias da Informação e Comunicação (TICs) vem ocorrendo nas diferentes esferas da sociedade, entre elas a educação. $\mathrm{O}$ autor alerta, entretanto, para a inversão no uso das tecnologias que, ao invés de se submeterem a objetivos humanos, participam de um processo contrário, isto é, o da submissão dos indivíduos a seus fins determinados.

Para analisarmos as perspectivas de formação humana presentes na proposição do Sistema Educacional Interativo no Pará, dividimos este artigo em quatro seções, além da Introdução. A primeira apresenta o percurso teórico-metodológico; a segunda aborda a educação e o processo de formação humana; a terceira discute o Sistema Educacional Interativo e a formação humana. Ao final, tecemos nossas conclusões.

\section{PERCURSO TEÓRICO-METODOLÓGICO}

Para a análise das perspectivas de formação humana presentes na proposta de educação estabelecida por meio do Sistema Educacional Interativo no Pará definimos como orientador do percurso teórico-metodológico a perspectiva materialista histórica dialética.

O materialismo histórico concebido por Marx é, conforme Rosenthal (1951), um instrumento de luta e organização do proletariado, constituindo um enfoque teórico-metodológico e analítico, para compreender a História como processo dinâmico e as grandes transformações da História e das sociedades humanas.

Segundo Kosik (2011), o materialismo histórico entende que a realidade social pode ser conhecida na sua concentricidade, pois quando se desvela a natureza da realidade social, eliminam-se as impressões advindas das experiências sensíveis e se reconhece a realidade social como uma unidade dialética de base e de superestrutura e o homem como sujeito histórico e social, de modo que para a realidade social ser conhecida em sua totalidade concreta é necessário o reconhecimento do homem como sujeito concreto. Por isso, afirma Marx (1983, p. 218):

O concreto é concreto por ser a síntese de múltiplas determinações, logo, unidade da diversidade. É por isso que ele é para o pensamento um processo de síntese, um resultado, e não um ponto de partida, apesar de ser o verdadeiro ponto de partida e, portanto, igualmente o ponto de partida da observação imediata e da representação. 
De acordo com Kosik (2011), é necessário reconhecer que o ponto de partida será sempre fornecido pela realidade, pelos fatos empíricos, que precisarão passar pela superação das impressões empíricas para ascender às questões fundamentais, de modo que o ponto de chegada não serão as primeiras representações do ponto de partida, mas o concreto pensado. A esse movimento Marx denominou dialética.

No tocante à dialética, Kosik (2011, p. 125) destaca, como princípio fundamental, o princípio da contradição, pois,

[...] a dialética materialista demonstra um sujeito concretamente histórico que cria, a partir do próprio fundamento materialmente econômico, ideias correspondentes e todo conjunto de formas de consciência. Não reduz a consciência as condições dadas; concentra a atenção no processo ao longo do qual o sujeito concreto produz e reproduz a realidade social; e ele próprio, ao mesmo tempo, é nela produzido.

Ainda em relação à dialética, Kosik (2011) adverte que, embora o princípio da dialética seja o da contradição, ela busca a totalidade, com esta última sendo entendida como produção social do homem. Para tanto, é necessário não apenas o conhecimento da realidade, mas a crítica e o conhecimento crítico para uma prática que altere e transforme a realidade anterior, no plano do conhecimento e no do histórico social. Dessa forma:

A dialética trata da "coisa em si". Mas a "coisa em si" não é uma coisa qualquer e, na verdade, não é nem mesmo uma coisa: a "coisa em si", de que trata a filosofia, é o homem e o seu lugar no universo, ou (o que em outras palavras exprime a mesma coisa): a totalidade do mundo revelada pelo homem na história e o homem que existe na totalidade do mundo (KOSIK, 2011, p. 250).

No que respeita ao percurso metodológico, optou-se pela pesquisa bibliográfica e documental. A pesquisa bibliográfica é importante para redefinir o encaminhamento da pesquisa, pois permite acesso à produção científica disponível sobre o tema decorrente de estudo anteriores, publicados em livros, artigos, teses, etc. (SEVERINO, 2007). A pesquisa documental, por sua vez, possibilita "[...] realizar alguns tipos de reconstrução, o documento escrito constitui, portanto, uma fonte preciosa para todo pesquisador nas ciências sociais" (CELLARD, 2008, p. 295).

De acordo com Cellard (2008), a noção de documento esteve atrelada, quase que exclusivamente, a textos e a arquivos oficiais, o que ocorria, principalmente, em virtude dos historiadores da época, que recorriam a esses instrumentos para realizar uma abordagem conjuntural focada, sobretudo, nos fatos e gestos dos governantes, sendo essa noção de documento ressignificada concomitantemente à própria revisão do campo da História, mais particularmente, pela Escola dos Annales. Nesse sentido, para o presente trabalho o documento

[...] consiste em todo texto escrito, manuscrito ou impresso, registrado em papel. Mais precisamente, consideraremos as fontes, primárias ou secundárias, que por definição são exploradas, e não criadas, em um contexto de procedimento da pesquisa (CELLARD, 2008, p. 297). 
A pesquisa envolveu documentos de natureza pública que, segundo Cellard (2008), consiste de documentação, geralmente volumosa, organizada de modo variável e destinado a diferentes sujeitos. A pesquisa realizada compreendeu a seguinte documentação:

- Lei no 9.394/1.996, Lei de Diretrizes e Bases da Educação.

- Plano de implantação do Sistema Educacional Interativo (SEI) e

- Parecer №. 205 do CEE/PA.

A seleção dos documentos anteriormente mencionados envolveu uma análise preliminar, pois, de acordo com Cellard (2008), esta avaliação implica a primeira etapa de toda análise documental, permitindo ao pesquisador compreender questões importantes sobre os documentos, a saber: o contexto de elaboração do documento, o autor ou autores, a autenticidade e confiabilidade do texto, natureza do texto e os conceitos-chave empregados, bem como a lógica do texto que organiza o documento. A análise preliminar ainda proporciona um

[...] encadeamento de ligações entre a problemática do pesquisador e as observações extraídas de sua documentação, o que lhe possibilita formular explicações plausíveis, produzir uma interpretação coerente, e realizar uma reconstrução de um aspecto qualquer de uma dada sociedade neste ou naquele momento (CELLARD, 2008, p. 297).

É possível, ainda, por meio da análise preliminar, realizar uma contínua reflexão, possibilitando a maturação de ideias e hipóteses que conduzam a explicações plausíveis. Assim,

uma análise confiável tenta cercar as questões, recorrendo a elementos provenientes, tanto quanto possível de fontes, pessoas ou grupos representando muitos interesses diferentes, de modo a obter um ponto de vista tão global e diversificado, quanto pode ser (CELLARD, 2008, p. 297).

Frigotto (2008) esclarece que, para que o processo de conhecimento seja dialético, a teoria fornece as categorias de análise necessárias ao processo da pesquisa. Nesse sentido, sob o prisma do método materialista histórico, a presente pesquisa demarca as seguintes categorias de análise: totalidade, contradição e mediação. Kosik (2011) enfatiza que o caminho da superação do todo, apresentado pela experiência, na representação e na opinião, configura uma "caótica representação do todo", pois a "rica totalidade da multiplicidade das determinações" coincide com a compreensão da realidade. Para que se possa conhecer o todo, porém, e explicá-lo, o homem precisa fazer um detóur: "o concreto se torna compreensível através da mediação do abstrato, o todo através da mediação da parte" (KOSIK, 2011. p. 36).

A categoria totalidade foi fundamental à análise das perspectivas de formação humana presentes na proposta de educação desenvolvida por meio do Sistema Educacional Interativo no Estado do Pará, visto que totalidade não significa todos os fatos. De acordo com Kosik (2011, p. 44), "totalidade significa: realidade como um todo estruturado, dialético, no qual ou do qual um fato qualquer (classe de fatos, conjunto de fatos) pode vir a ser racionalmente compreendido". 
A contradição é uma categoria essencial para o conhecimento da totalidade, no caso, o projeto de instituição do SEI. A contradição é inerente à sociedade capitalista, pois, no sistema capitalista haverá sempre interesses antagônicos: de um lado, os interesses dos donos dos meios de produção e, de outro, os interesses dos trabalhadores que vendem sua força de trabalho para o capital. Para Kosik (2011, p. 60), "[...] a totalidade sem contradição é vazia e inerte, as contradições sem totalidade são formais e arbitrarias".

A categoria mediação vai permear todas as demais categorias, pois, ainda segundo Kosik (2011), o concreto somente é compreensível por meio da mediação do abstrato e o todo por meio da mediação das partes. Para melhor compreensão, citamos, a título de exemplo, o trabalho que é mediado pela relação homem-natureza. Assim, analisar o uso das Tecnologias da Informação e Comunicação no Sistema Educacional Interativo como momento para a promoção da formação humana é fundamental, visto essa constituir uma mediação entre o ensino e aprendizagem, entre o abstrato e o concreto, pois a mediação permite compreender que nada é isolado da totalidade social, toda a sociedade e seus nexos mantêm uma relação dialética com a existência real.

\section{A educação e o processo de formação humana}

Pensar a formação humana constitui uma tarefa complexa, exigindo pensar a realidade para além de sua imediatidade no real sensível, imediato. Requer, sobretudo, compreender a realidade a ser construída. Nesse sentido, "a formação humana está fundada numa ontologia concreta e numa gnoseologia que possibilita à classe subalterna compreender as contradições da sociedade capitalista e elaborar sua própria emancipação". (ANGELI, 2009, p. 13).

A formação humana tem conduzido a discussão de vários pensadores. Foi Gramsci, no entanto, quem elaborou a complexa teoria sobre a formação humana ao defender a necessidade da formação do novo homem.

O novo humano para ele será crítico, isto é, capaz de compreender as contradições do desenvolvimento sócio e econômico e das relações de forças políticas que atuam nesta sociedade; e criativo, isto é, ser capaz de superar o senso comum, presente no processo de desorganização do indivíduo e dos grupos subalternos, impossibilitando-os de compreender suas próprias identidades (ANGELI, 2009, p. 13).

Assim, a formação humana cumpre papel fundamental no concernente à emancipação dos sujeitos. É por meio dela que os grupos subalternos podem perceber as contradições da sociedade capitalista e criar estratégias para sua superação. Faz-se necessário, contudo, esclarecer que, para Gramsci, a formação desse novo homem só é possível por meio da filosofia da práxis, haja vista esta ter como objetivo principal elevar a consciência crítica das classes populares, criando um contato direto entre o intelectual e as classes subalternas e, ainda, compreender a real unidade entre teoria e prática.

Angeli (2009) esclarece que Gramsci concebe a formação do homem como histórica e dialética de modo a superar a distinção pedagógica burguesa entre cultura humanística e cultura técnica, distinção que reflete a divisão social do trabalho. Gramsci en- 
tende a formação humana como possibilidade de construir intelectuais que se enlaçam às massas, isto é, os intelectuais orgânicos que, além de compreender o saber, sintam os problemas enfrentados pelas classes populares. Angeli $(2009$, p. 18$)$ elucida que:

Uma autoconsciência crítica acontece quando a massa historicamente e politicamente elabora sua própria categoria de intelectuais, quando esses exprimem autonomamente a sua própria concepção de mundo, uma vez comprometido com as classes subalternas.

Cabe destacar que a formação humana não ocorre espontaneamente, imediata e mecanicamente, pela transformação pura e simples das estruturas produtivas, mas mediada pelas lutas de enfrentamento entre as classes. A formação humana das classes subalternas, no entanto, não poderá estar desvinculada da práxis emancipadora dos trabalhadores e, consequentemente, transformadora das atuais condições da sociedade capitalista. (ANGELI, 2009).

A formação humana constitui um dos preceitos da Constituição Federal de 1988, tal como consta em seu artigo 205:

A educação, direito de todos e dever do Estado e da família, será promovida e incentivada com a colaboração da sociedade, visando ao pleno desenvolvimento da pessoa, seu preparo para o exercício da cidadania e sua qualificação para o trabaIho (BRASIL, 1988).

Também na Lei de Diretrizes e Bases da Educação (LDBEN) 9.394/1996, conforme estabelecido em seu artigo 35, Inciso III, que trata do Ensino Médio, lemos que:

O ensino médio, etapa final da educação básica, com duração mínima de três anos, terá como finalidades [...] III - o aprimoramento do educando como pessoa humana, incluindo a formação ética e o desenvolvimento da autonomia intelectual e do pensamento crítico (BRASIL, 1996, p. 24).

Saviani (2003b) esclarece que nem sempre a escola foi o "centro" da formação humana, pois, inicialmente, os homens educavam-se coletivamente, mediados pelo trabaIho e, ao transformar a natureza, construíam-se como sujeitos sociais. Logo, os homens apropriavam-se, coletivamente, dos meios de produção de sua existência, constituindo o trabalho um ato educativo. Com o surgimento da sociedade burguesa ocorre o deslocamento do eixo de produção do campo para a cidade, da agricultura para a indústria. É então que a escola passa a ser o local precípuo da formação humana, tornando-se, nesse contexto, uma necessidade social, pois, sob a formação social capitalista, os trabalhadores precisam ter o mínimo de conhecimento técnico para operar com os novos meios de produção.

Para Saviani (2003b), a formação humana, na sociedade capitalista, passa pela possibilidade de a escola garantir o acesso das novas gerações ao saber sistematizado, ao saber metódico e científico, acreditando que, por meio do acesso aos saberes historicamente produzidos, a classe trabalhadora compreenda o processo de produção e assim transforme a sociedade. $O$ autor reitera que o saber é objeto específico do trabalho escolar. Assim, a essência do trabalho educativo consiste no 
[...] ato de produzir, direta e intencionalmente, em cada indivíduo singular, a humanidade que é produzida histórica e coletivamente pelo conjunto dos homens. Assim, o objeto da educação diz respeito, de um lado, à identificação dos elementos culturais que precisam ser assimilados pelos indivíduos da espécie humana para que eles se tornem humanos e, de outro lado e concomitantemente, à descoberta das formas mais adequadas para atingir esse objetivo (SAVIANI, 2003b, p. 13).

Saviani (2003b) propõe a pedagogia histórico-crítica como a aquela capaz de propiciar uma formação que possibilita a transformação da realidade social. Pautada no materialismo histórico dialético, a pedagogia histórico-crítica defende que não há como compreender os fenômenos humanos e sociais em sua totalidade desconhecendo o contexto histórico em que estes ocorrem.

Na concepção de Saviani (2003a), a experiência imediata não permite à classe trabalhadora conceber as desigualdades sociais como produzidas pelas relações de produção da vida material. Compreende-se então a importância da escola, pois é ela a promotora da mediação do saber espontâneo ao saber sistematizado, da cultura popular à cultura erudita.

Na perspectiva da pedagogia histórico-crítica, a formação humana deve contribuir para o desenvolvimento da consciência crítica dos estudantes diante das relações sociais que produzem sua própria desumanidade. Daí a importância de a escola propiciar o contato do aluno concreto com os conhecimentos sistematizados, pois este aluno concreto situa-se em uma sociedade que exige o domínio deste tipo de conhecimento. Assim sendo, os conteúdos históricos na formação humana sempre serão importantes e, em certa maneira, determinantes "porque é pelo caminho deles que se apreende as perspectivas históricas, o modo de situar-se historicamente" (SAVIANI, 2003b, p. 145). Assim, se a escola não permite o acesso aos saberes sistematizados, os trabalhadores ficam bloqueados e impedidos de ascender ao nível da elaboração do saber, embora participem de sua produção por meio de sua prática cotidiana, irreflexiva. "O saber continua a ser propriedade privada a serviço do grupo dominante" (SAVIANI, 2003b, p. 77).

Saviani (2003a) adverte, ainda, para o esvaziamento da formação humana pelas pedagogias não críticas (pedagogia tradicional, pedagogia nova e pedagogia tecnicista), que, pautadas no ideário do liberalismo burguês, têm na figura central do professor (pedagogia tradicional), do aluno (pedagogia nova) e das técnicas de ensino (pedagogia tecnicista), a organização gradual e lógica dos saberes culturais que deveriam ser transmitidos aos alunos sem questionar seus objetivos sociais e políticos e tampouco sua relação com a realidade concreta.

Manacorda (2010), ao apontar as fragilidades da pedagogia tradicional na formação humana, enfatiza que o determinismo ambiental reduzia o homem a um processo formativo limitado, definido pelas condições sociais. $\mathrm{O}$ autor reconhece que a pedagogia nova representou uma ruptura com a pedagogia tradicional, porém manteve-se limitada a um desenvolvimento espontâneo, pondo o homem frente a si mesmo e não frente ao mundo concreto das coisas e das relações sociais. Afirma o autor: "Substituem o processo educativo heterônomo por um processo autônomo, que é igualmente limitado" (MANACORDA, 2010, p. 117). 
Na pedagogia tecnicista a formação humana caracteriza-se pela racionalização do trabalho pedagógico, mediante a tentativa de anulação das interferências subjetivas para garantir a objetividade e eficiência no sistema educacional, tal qual o sistema de produção. Segundo Saviani (2003a), a pedagogia tecnicista, ao tentar transpor para a escola o funcionamento do sistema fabril, perdeu de vista a especificidade da educação, ignorando que a articulação entre escola e processos produtivos se dá por mediações indiretas. Entre essas especificidades Lombardi (2011) defende que cabe à educação propiciar aos homens o desenvolvimento integral de todas as potencialidades humanas, considerando que

[...] todas as necessidades do homem devem emergir no processo educacional, tais como a busca pela sobrevivência, o prazer, a criação e o gozo da cultura, a participação na vida social, a interação com os outros homens, a autorrealização e a autocriação (LOMBARDI, 2011, p. 17).

Manacorda (2010) destaca a importância da formação humana na constituição do próprio homem, pois este constitui-se como homem a partir de suas experiências, interações e modificação da natureza. Ao modificar a natureza, o homem se diferencia dos outros animais: ele cria o mundo humano que, mediado pelo trabalho, produz o mundo da cultura de modo que a educação se constitui em fenômeno próprio dos seres humanos, o que significa afirmar que, além de ser uma exigência para o processo de trabalho, ela se materializa por meio do trabalho.

Nesse sentido, a humanidade do homem não é inata, mas historicamente produzida, mediada pelo trabalho e pela relação com outros homens, com a escola sendo promotora da formação humana por meio dos conhecimentos por ela socializados. Assim, uma escola comprometida com a superação das desigualdades produzidas pela sociedade capitalista deve estar empenhada com a formação de um homem capaz de sentir, saber e compreender sua realidade para transformá-la.

\section{O Sistema Educacional Interativo e a formação humana}

O SEI foi aprovado pela Resolução no. 202, de 25 de abril de 2017 (PARÁ, 2017c), consubstanciado no Parecer no. 205, de 6 de abril de 2017, da Câmara de Educação Básica do Conselho Estadual de Educação (CEB/CEE). De acordo com o referido Parecer (PARÁ, 2017a), o SEI mantém características do Ensino Médio presencial, pois o uso da tecnologia não afeta a junção de alunos em turmas regulares, a frequência diária à sala de aula e o controle e obrigatoriedade da frequência. A parecerista fundamenta-se na Lei $n^{\circ}$ 13.415/2017 para a instituição do Ensino Médio por meio de mediação tecnológica, bem como na LDB no. 9.394/1.996, Artigo 36, parágrafo 11:

[...] § 11. Para efeito de cumprimento das exigências curriculares do ensino médio, os sistemas de ensino poderão reconhecer competências e firmar convênios com instituições de educação a distância com notório reconhecimento, mediante as seguintes formas de comprovação:

[...] VI - cursos realizados por meio de educação a distância ou educação presencial mediada por tecnologias (BRASIL, 1996).

Ainda conforme a parecerista, este dispositivo legal viabiliza a instalação do SEI, pois não haverá prejuízos na integralização curricular do Ensino Médio, utilizando-se cursos a distância ou presenciais mediados por tecnologias (PARÁ 2017a). 
O currículo trabalhado no SEI, por sua vez, de acordo com o Plano de Instalação, sustenta-se nas Diretrizes Curriculares Nacionais do Ensino Médio, nos Parâmetros Curriculares Nacionais e na Legislação Educacional vigente "[...] garantindo ao aluno das comunidades preferencialmente rurais dos municípios paraenses, o acesso à última fase da Educação Básica, que constitui direito atribuído a todo aluno brasileiro" (PARÁ, 2017a, p. 5).

O SEl adota a Organização Curricular do Ensino Médio e a matriz curricular vigente na rede estadual de educação. Também adota os dispositivos legais que exigem a oferta de no mínimo 1.200 (um mil e duzentas) horas de atividades presenciais distribuídas em no mínimo 200 (duzentos) dias letivos. As aulas são planejadas antecipadamente "[...] obedecendo rigidamente à sequência de desenvolvimento conceitual, procedimental e atitudinal que permeiam a organização dos conteúdos do Ensino Médio segundo as orientações dos PCNs do Ensino Médio" (PARÁ, 2017b, p. 25). No planejamento são utilizados material ilustrativo e visual, havendo a possibilidade de [...] "'gravações de aulas' externas sempre que necessárias para melhor ilustração do caráter procedimental que por-ventura caracterizarem os conteúdos de ensino [...]". (PARÁ, 2017b, p. 25). Consta, igualmente, no referido Plano, que as aulas televisivas deverão ser organizadas da seguinte forma: "Enunciado do Conteúdo Principal; Habilidades; Competências; Unidades temáticas; Avaliação; Descrição de recursos utilizados; Dinâmica local interativa (Atividades e exercícios); Interatividade final" (PARÁ, 2017b, p. 26).

Ao analisarmos a concepção de formação humana presente no SEl deparamo-nos com a superficialidade com que o currículo é tratado de forma geral e, principalmente, quanto à formação humana. $O$ documento apresenta mais informações sobre as estratégias de execução do projeto do que sobre as bases teóricas que fundamentam a referida proposta metodológica.

O projeto concebe o currículo como um rol de conteúdos organizados de forma disciplinar a ser desenvolvido nas teleaulas. Os conteúdos de ensino previstos são selecionados por especialistas e planejados antecipadamente pelos professores, no âmbito da coordenação estadual do projeto, conforme consta no Plano de Implantação:

[...] a Coordenação Pedagógica do SEl, sediada na Seduc, fornecerá a proposta curricular dos componentes curriculares pertinentes a cada série do Ensino Médio, aos professores ministrantes, responsáveis e produtores acadêmicos das aulas e do material pedagógico de apoio (textos complementares e roteirização das aulas) a serem utilizados por todos em sala de aula, de modo que não haja dificuldades de acompanhamento aos conteúdos curriculares. Todo material elaborado será antecipadamente entregue à coordenação pedagógica, que os destinará aos professores presenciais e respectivos alunos, facilitando o entendimento e sincronização das informações, no processo de ensino e aprendizagem (PARÁ, 2017b, p. 30).

A forma de organização do conhecimento no SEI demonstra o aparelhamento do currículo com as orientações de organismos internacionais, impondo aos Estados nacionais novas políticas curriculares. O SEl é financiado pelo Banco Interamericano de Desenvolvimento, conforme noticiado pela Assessoria de Comunicação da Fundação da Amazônia de Amparo a Estudos e Pesquisas do Estado do Pará (Fapespa). ${ }^{6}$

ASSESSORIA DE COMUNICAÇÃO FAPESPA. Fapespa e SEI firmam parceria em prol da educação com tecnologia no Estado do Pará. 8/5/2019. Disponível em: http://www.fapespa.pa.gov.br/noticia/1596. Acesso em: 20 jan. 2020. 
Com um investimento global de $\mathrm{R} \$ 15,3$ milhões, o SEl integra o Programa de MeIhoria da Qualidade e Expansão de Cobertura da Educação Básica, implantado pela Seduc com financiamento do Banco Interamericano de Desenvolvimento (BID) e concebido no âmbito do Pacto Pela Educação.

As reformas de ensino atreladas aos rearranjos do capitalismo têm tido influência das organizações multilaterais, pois, "quando o capitalismo se altera, o papel da escola também sofre modificações. Além disso, a escola não atua de maneira perfeita na construção da reprodução - como um aparelho do Estado, ela também é marcada por contradições e conflitos" (CARNOY, 1986, p. 63). O SEI faz parte do Programa de Melhoria e Expansão do Ensino Médio: projeto escola jovem, financiado pelo Banco Interamericano de Desenvolvimento (BID), lançado no Brasil em 2000 tendo como finalidade

[...] apoiar a implementação da reforma curricular e estrutural e a expansão do atendimento no ensino médio pelas Unidades da Federação do país, visando à meIhoria de sua qualidade e à ampliação de seu grau de cobertura, como forma de garantir maior equidade social (BRASIL, 2000, p. 3).

As ações de financiamento dos organismos internacionais são dotadas de intencionalidades que ultrapassam as questões econômicas e se inserem, sobretudo, no campo educacional. Os projetos executados no Brasil têm atingido a Educação Básica como um todo, embora historicamente o foco tenha sido o Ensino Fundamental. Nas últimas décadas, todavia, o Ensino Médio tem sido alvo das ações de tais instituições financeiras. De acordo com Coraggio (apud HADDAD, 2008, p. 27), há

[...] uma correlação entre sistema educativo e sistema de mercado, entre escola e empresa, entre pais e consumidores de serviços, entre relações pedagógicas e relações de insumo-produto, entre aprendizagem e produto, esquecendo aspectos essenciais próprios da realidade educativa.

O foco no Ensino médio tem como intenção a definição de conhecimentos que atendam, sobretudo, aos interesses político-econômicos capitalistas para a formação dos trabalhadores. Essa interferência representa uma nova forma de se conceber a educação e o currículo. Segundo Haddad (2008), os programas dos governos federal e estaduais financiados por instituições financeiras são formulados com pouca participação da sociedade civil brasileira, sobretudo quando se trata da definição de currículos.

A centralização da seleção do currículo na mão de um grupo de especialistas da área financeira deixa claro que os organismos internacionais têm como prioridade interferir na formação da classe trabalhadora. Assim é que a Lei no 13.415/2017 (BRASIL, 2017) que institui a Política de Fomento à Implementação de Escolas de Ensino Médio em Tempo Integral ${ }^{7}$

\footnotetext{
A seguir, inserirmos artigos e parágrafos da referida Lei que fundamentam nossas afirmações: "Art. 36 §6o A critério dos sistemas de ensino, a oferta de formação com ênfase técnica e profissional considerará: I - a inclusão de vivências práticas de trabalho no setor produtivo ou em ambientes de simulação, estabelecendo parcerias e fazendo uso, quando aplicável, de instrumentos estabelecidos pela legislação sobre aprendizagem profissional; II - a possibilidade de concessão de certificados intermediários de qualificação para o trabalho, quando a formação for estruturada e organizada em etapas com terminalidade. [...]; §9o As instituições de ensino emitirão certificado com validade nacional, que habilitará o concluinte do Ensino Médio ao prosseguimento dos estudos em nível superior ou em outros cursos ou formações para os quais a conclusão do Ensino Médio seja etapa obrigatória. Além das formas de organização previstas no artigo 23, o Ensino Médio poderá ser organizado em módulos e adotar o sistema de créditos com terminalidade específica. §11 Para efeito de cumprimento das exigências curriculares do Ensino Médio, os sistemas de ensino poderão reconhecer competências e firmar convênios com instituições de educação a distância com notório reconhecimento [...]" (BRASIL, 2017).
} 
[...] deixa aberta a possibilidade das atividades de formação técnica profissional, vivências e experimentação poderem ser executadas de forma terceirizada, abre-se um campo gigantesco para a iniciativa privada invadir o ensino público e ditar, em alguns casos, as regras de desenvolvimento desta etapa em nome "dos interesses do mercado" (CARVALHO; SOARES; SALOMÉ, 2017, p. 17.958).

Ao flexibilizar a formação de nível médio, o Estado permite a adoção de formatos diferenciados para o acesso ao Ensino Médio. O SEI insere-se nesse contexto como alternativa de acesso à educação no Pará. Ao eleger um projeto que utiliza o tele-ensino para ministrar os conteúdos curriculares aos alunos das comunidades rurais, selecionam-se concepções de formação, ser humano, de escola e sociedade que se pretendem hegemônicas.

Neste aspecto, é importante destacar que a formação humana presente no SEI volta-se ao desenvolvimento de competências. Conforme Albino e Silva (2019, p. 140), "A formação por competências visa à preparação do homem para atender às condições contemporâneas de produção de bens e serviços em suas novas formas de organização do trabalho". Ou seja, demanda uma nova perspectiva de formação para a classe trabaIhadora cuja finalidade é atender às necessidades do capital.

Adaptar a formação humana às demandas do mercado de trabalho esvazia a finalidade geral da educação básica nos termos estabelecidos na LDBEN №. 9.394/1.996. De acordo com Silva (2008, p. 114), "a finalidade de uma educação que se volta para o 'aprender a fazer' possui como referência a noção de competência e vincula a educação diretamente às razões do mercado de trabalho".

Nesta perspectiva, Frigotto (2010a) chama a atenção para os processos de precarização da formação da classe trabalhadora.

Os pacotes de ensino assepticamente programados por especialistas, cuja forma de veiculá-lo é tida como mais relevante que os próprios conteúdos, e a hierarquização e o parcelamento do processo pedagógico constituem-se em formas de controle da produção e divulgação do saber que se processa na escola e, enquanto tais, de controle social mais amplo. Sob esta ótica, o aumento do acesso à escola, ou até mesmo dos anos de escolaridade - no interior de uma instituição hierarquizada e desqualificada que promove uma "meia-educação" - torna-se amplamente funcional e produtivo para a estabilidade do sistema social geral (p. 192).

A garantia da educação na condição de política pública, como um dos direitos da cidadania nas localidades distantes dos centros urbanos é uma demanda das comunidades que foram, historicamente, excluídas da educação formal. A forma proposta pelo SEI para garantia deste direito constitucional, todavia, leva-nos a problematizar os interesses que motivam tal propósito. Observa-se que a preocupação está centrada na oferta de vagas, no atendimento da demanda reprimida no Estado que, por meio de sua rede física de escolas, não consegue atender ao quantitativo de alunos aptos a ingressar no Ensino Médio, conforme consta no Plano de Implantação.

Trata-se, portanto, de uma ação de impacto efetivo e imediato para a administração central com largo alcance social ampliando a oferta de vagas do Ensino Médio com efetivo atendimento à demanda reprimida nos municípios e em especial nas comunidades rurais (ribeirinhos e quilombolas), disponibilizando uma infraestrutu- 
ra de suporte aos gestores do poder público, via comunicação social, e promovendo a inclusão digital dos cidadãos dos municípios e respectivas comunidades rurais por meio do acesso à Internet com utilização de tecnologia satelital, corroborando eficazmente para a expansão do Ensino Médio da Rede de Ensino do Estado do Pará (PARÁ, 2017b, p. 7).

O SEI, portanto, foi pensando especialmente para atender às comunidades rurais, sobretudo ribeirinhos, quilombolas e comunidades tradicionais de difícil acesso, no entanto percebe-se que o seu processo de execução está ligado à redução de investimentos na educação pública, aprofundando a precarização do trabalho docente e consequentemente promovendo uma formação pouco efetiva na transformação das bases que sustentam a sociedade capitalista.

Desse modo, confirma-se o que Caldart (2004, p. 151) prognosticou: “[...] na história do Brasil, toda vez que houve alguma sinalização de política educacional ou de projeto pedagógico específico, isto foi feito para o meio rural e poucas vezes com os sujeitos do campo". A autora acrescenta, ainda, que sucessivos governos tentaram submeter os povos do campo "[...] a um tipo de educação domesticadora e atrelada a modelos econômicos perversos" (2004, p. 151).

Expandir a rede estadual de educação por meio do acesso ao Ensino Médio a jovens de diversas comunidades por meio do projeto SEl é preocupante, haja vista sua instituição não incluir a construção de novas escolas. O projeto prevê convênio com os municípios cuja contrapartida do Estado do Pará é apenas o suporte tecnológico e os docentes. É deste modo, portanto, que o Pará propõe ampliar o número de vagas no Ensino Médio para atender à demanda e melhorar os indicadores educacionais, além de promover a inclusão digital das comunidades rurais.

O alcance deste aparato tecnológico aos mais distantes lugares do Estado do Pará é uma questão que também precisa ser analisada, mas não é objeto deste artigo. Por sua vez, é preocupante a estratégia metodológica que a Secretaria de Estado de Educação do Pará propõe como solução para garantir acesso à educação às populações de jovens que moram em comunidades rurais em que não há oferta regular de Ensino Médio ou a demanda é superior ao número de vagas oferecidas pelo Estado.

Ferreira (2015, p. 89) enfatiza a importância de compreender o uso das TICs em seu contexto, o social, e que seu uso na educação deve ser tratado em sua historicidade, pois em

um mundo onde o acesso aos bens culturais é negado à imensa maioria da população, resulta, contraditoriamente, que as possibilidades de formação humana estarão sempre - enquanto persistirem as relações sociais de corte capitalista - limitadas ao desenvolvimento unilateral.

Enquanto atividade-meio, o uso das TICs na educação só faz sentido se viabilizarem o domínio dos conhecimentos produzidos historicamente. O conhecimento como processo de desenvolvimento humano, ou seja, formação humana,

[...] emerge, então, como uma comunicação entre pessoas livres em graus diferentes de maturação humana. Nessa formulação, o valor da educação expressa-se como promoção do homem. Enunciamos, então, uma primeira definição de educa- 
ção: a educação, enquanto comunicação entre pessoas livres em graus diferentes de maturação humana, é promoção do homem, de parte a parte - isto é, tanto do educando como do educador (SAVIANI; DUARTE, 2010, p. 423).

A educação para a formação humana "[...] coincide, nessa acepção, com o processo de promoção humana levado a efeito pela educação" (SAVIANI; DUARTE, 2010, p. 423). Ou seja, a educação é o processo pelo qual a humanidade consegue promover o homem à condição de sujeito histórico, social, político, cultural, capaz de construir as bases para uma sociedade mais justa. Propostas pedagógicas como a do SEI, no entanto, vão na contramão deste processo, revisitam concepções educacionais que não priorizam a dimensão da formação humana, somente valorizam o saber fazer e a dimensão técnica.

No SEl observamos a prevalência da concepção tecnicista de ensino, a qual tem como base os pressupostos da neutralidade científica e como princípios a "[...] racionalidade, eficiência e produtividade, essa pedagogia advoga a reordenação do processo educativo de maneira a torná-lo objetivo e operacional" (SAVIANI, 1982, p. 11). Ainda de acordo com Saviani (1982), esta concepção de educação pretende a objetivação do trabalho pedagógico, a mecanização do processo educativo. Afirma o autor:

Daí a proliferação de propostas pedagógicas tais como o enfoque sistêmico, o microensino, o tele-ensino, a instrução programada, as máquinas de ensinar, etc. Daí, também, o parcelamento do trabalho pedagógico com a especialização das funções, postulando-se a introdução no sistema de ensino de técnicos dos mais diferentes matizes. Daí enfim a padronização do sistema de ensino a partir de esquemas de planejamento previamente formulados aos quais devem se ajustar as diferentes modalidades de disciplinas e práticas pedagógicas (SAVIANI, 1982, p. 11).

A expansão do Ensino Médio de forma regular por meio do SEI coloca em evidência a estratégia de ensino que o Estado do Pará utiliza na formação do trabalhador. De acordo com Arroyo (apud FRIGOTTO, 2010a, p. 183):

O mais grave na relação entre escola e a formação da classe trabalhadora no Brasil é que se fez tudo para que o trabalhador não fosse educado, não dominasse a língua, não conhecesse sua história, não tivesse a seu alcance instrumentos para elaborar e explicar o seu saber, sua ciência e sua consciência.

Esta estratégia metodológica não atende nem às demandas impostas pelo próprio sistema capitalista, que requer trabalhadores qualificados, que saibam liderar, trabalhar em equipe, etc., menos ainda às demandas da classe trabalhadora que não tem possibilidade, por meio desta formação, de desenvolver sua consciência como classe social e ainda menos de contribuir com a formação de intelectuais capazes de colaborar para a superação das desigualdades sociais provocadas pelo modelo econômico vigente.

A escola, na qualidade de instituição social, é lugar de contradição, por isso é importante compreender que "Concretamente, a questão da desqualificação da escola é, antes de tudo, uma desqualificação para a escola frequentada pela classe trabalhadora" [...]. (FRIGOTTO, 2010a, p. 186). Assim, o capitalismo vem atuando para manter o saber escolar e a hegemonia da burguesia, por isso, oferecer para a classe trabalhadora 
uma escolaridade elementar que permita um mínimo de cálculo, leitura e escrita, e o desenvolvimento de determinados traços socioculturais, políticos e ideológicos tornam-se necessários para a funcionalidade das empresas produtivas e organizações em geral, como também para a instauração de uma mentalidade consumista (FRIGOTTO, 2010a, p. 184).

A negação de uma educação que desenvolva a formação humana tem por objetivo a manutenção do status quo, por meio de um Ensino Médio que ofereça uma educação dualista. A escola para a classe trabalhadora tem desempenhado a tarefa de formar para o mercado de trabalho atendendo às necessidades do capital lhe "entregando" a mão de obra necessária para operar o sistema. Neste aspecto, o conhecimento produzido pelo homem é utilizado para distanciá-lo de sua humanidade. Carnoy (1986, p. 10) observa que "com o progresso tecnológico, o conhecimento torna-se mais do que nunca um instrumento de dominação social". Nesse sentido, somente por meio da assimilação dos conhecimentos produzidos pela humanidade a classe trabalhadora poderá compreender que sua condição de explorada, oprimida, etc., não é algo dado, natural, mas produzida historicamente nas relações desiguais advindas do sistema capitalista (SAVIANI, 2003b).

Embora se reconheça que a escola tem atuado em favor dos interesses de um determinado grupo, Mészáros (2008) sugere caminhos que possibilitem uma educação radical que contribua para a transformação e superação da sociedade capitalista.

A educação para além do capital visa uma ordem social qualitativamente diferente. Agora não só é factível lançar-se pelo caminho como também é necessário e urgente. Pois as incorrigíveis determinações destrutivas da ordem existente tornam imperativo contrapor aos irreconciliáveis antagonismos estruturais do sistema do capital uma alternativa concreta e sustentável para regulação da reprodução metabólica social, se quisermos garantir condições elementares da sobrevivência humana. O papel da educação, orientado pela única perspectiva efetivamente viável de ir para além do capital, é absolutamente crucial para esse propósito (MÉSZÁROS, 2008, p. 71-72).

Mészáros (2008) acredita que, por meio da educação, é possível a superação da sociedade capitalista, porém essa educação precisar estar verdadeiramente comprometida com a formação da classe trabalhadora, comungando com Kosik (2011), que entende a formação do homem como ser social, em que sua essência consiste na unidade da objetividade e da subjetividade. Kosik (2011) concebe o presente como um meio para a realização do futuro, de modo que a formação humana precisa estar atrelada à realidade, porém a realidade não pode ser confundida com cotidianidade que no sistema capitalista passa a ter uma atmosfera natural, sem promover a indagação do sentido dessa cotidianidade, pois é necessário compreender que ela é produzida pelos detentores dos meios de produção.

Para Frigotto (2010b) o desenvolvimento da formação humana requer a construção da escola pública unitária e politécnica que ofereça à classe trabalhadora as condições objetivas e subjetivas para a formação da omnilateralidade

No contexto dos embates que se travam hoje na sociedade brasileira na busca de romper com todas as formas de exclusão social e, nos interstícios das possibilidades concretas de construir-se um industrialismo de novo tipo e processos educati- 
vos não imediatistas que concorram para a formação omnilateral e, portanto, para os processos de emancipação humana, a busca do sentido "radical" de escola unitária, no plano do conhecimento e no plano político-organizativo, é fundamental (FRIGOTTO, 2010b, p. 188).

A base para uma educação omnilateral, que busca o desenvolvimento integral das potencialidades humanas, não separa a formação intelectual da formação para o trabaIho manual, a concepção e a execução, isto é, o trabalhador não irá simplesmente executar tarefas sem ter ideia da concepção de trabalho que as fundamenta. A afirmação de educação omnilateral perpassa pela superação da unilateralidade da educação em que os filhos das classes subalternas recebem uma formação que os direciona para o mercado de trabalho enquanto os filhos da elite recebem uma educação propedêutica, mantendo-os donos dos meios de produção. Nessa perspectiva, para a superação das desigualdades entre a educação das classes subalternas e a educação direcionada para os herdeiros do capital faz-se necessária a defesa de uma escola unitária que forme para o mundo do trabalho em que a omnilateralidade se constitua o objetivo central da formação humana.

\section{CONCLUSÃO}

O Ensino Médio tem ocupado lugar de destaque nas políticas educacionais. A razão para tal centralidade encontra-se estritamente ligada à própria finalidade deste nível de ensino, a saber: o aprimoramento do educando como pessoa humana, incluindo a formação ética e o desenvolvimento da autonomia intelectual e do pensamento crítico e sua formação para o mundo do trabalho, conforme consta na LDBEN 9.394/1996, artigo 35, inciso III. As políticas educacionais alinhadas às orientações dos organismos multilaterais, contudo, têm buscado atender às demandas do mercado de trabalho em detrimento da formação plena do homem, distanciando-o do mundo do trabalho enquanto processo formativo de sua própria humanidade.

O Sistema Educacional Interativo é apresentado como sendo uma metodologia de ensino adotada pela Secretaria de Educação do Estado do Pará (Seduc) para atender às comunidades rurais de difícil acesso e/ou com falta de professores com formação para atuar no Ensino Médio. Cabe destacar, porém, que o SEI é mais que uma metodologia de ensino, constituindo, antes, um projeto de formação que, direcionado aos filhos da classe trabalhadora, vem substituindo o Sistema Modular de Ensino (Some), política adotada para a expansão da oferta do Ensino Médio no interior do Estado do Pará desde a década de 80 .

Assim, não se pode afirmar que o SEI - financiado que é pelo Banco Interamericano de Desenvolvimento e concebido no âmbito do Pacto Pela Educação - constitua um projeto voltado à emancipação das classes subalternas. Antes, ele é funcional à reconstrução das bases que sustentam a sociedade capitalista.

Dessa forma, além de não possibilitar a formação do novo homem, tal como defendido por Gramsci, aprofunda ainda mais as desigualdades sociais e regionais ao agenciar uma política educacional diferenciada para o meio rural, que promove a fragmentação do trabalho manual/intelectual e com qualidade duvidosa, pouco efetiva no desenvolvimento da formação omnilateral das populações que, historicamente, tiveram 
negado seu direito de ter acesso aos conhecimentos produzidos pela humanidade. A metodologia utilizada para garantir a oferta de Ensino Médio nas comunidades rurais pouco ou nada colaborará para a reflexão acerca da realidade objetiva desses sujeitos e, consequentemente, para sua transformação, colaborando para legitimar uma proposta de ensino que não atende às demandas das comunidades no que diz respeito à necessidade de uma educação que transforme as condições de desumanização presentes no campo.

Assim, a formação proposta pelo SEI pouco contribuirá para a formação de sujeitos críticos, visto que uma educação que nega o desenvolvimento da formação humana, isto é, o não desenvolvimento pleno de diferentes habilidades: física, motora, artística, intelectual e cognitiva, da omnilateralidade, está comprometida com a manutenção do status quo. A educação na perspectiva da omnilateralidade configura-se como condição necessária para o livre desenvolvimento do homem como ser crítico, dotado de uma formação verdadeiramente humana. Esta é uma condição imperativa para a superação do modelo capitalista e a construção de uma sociedade que restabeleça a relação do homem com o trabalho como promotor de sua humanidade.

A formação da classe trabalhadora somente será na perspectiva do desenvolvimento humano por meio de uma educação capaz de transpor a concepção burguesa de sociedade que restringe o resgate do homem na sua omnilateralidade.

\section{REFERÊNCIAS}

ABRANTES, Angelo Antonio. Com ensinar? O método da pedagogia histórico-crítica e a aula como unidade concreta de relações sociais. In: PASQUALINI, Juliana Campregher; AGUDO, Marcela de Moraes; TEIXEIRA, Lucas André (org.). Pedagogia histórico-crítica: legado e perspectivas. Uberlândia: Navegando Publicações, 2018.

ALBINO, Ângela Cristina Alves; SILVA, Andréia Ferreira da. BNCC e BNC da formação de professores: repensando a formação por competências. Revista Retratos da Escola, Brasília, v. 13, n. 25, p. 137-153, jan./ maio 2019. Disponível em: http://retratosdaescola.emnuvens.com.br/rde/article/view/966. Acesso em: 19 maio 2020.

ANGELI, José Mario. Princípio da formação humana: a filosofia da práxis. In: PLATT, Adreana Dulcina (org.). Currículo e formação humana: princípios, saberes e gestão. 1. ed. Curitiba: Editora CRV, 2009.

BRASIL. Constituição Federal de 1988. Disponível em http://www.planalto.gov.br/ccivil_03/Constituicao/ Constituicao.htm. Acesso em: 20 fev. 2020.

BRASIL. Conselho Nacional de Educação. Lei № 9.394/1996. Estabelece as diretrizes e bases da educação nacional. Disponível em: http://www.planalto.gov.br/ccivil_03/Leis/L9394.htm. Acesso em: 24. fev. 2020. BRASIL. Conselho Nacional de Educação. Lei № 13.415, de 16 de fevereiro de 2017. Disponível em: http:// www.planalto.gov.br/ccivil_03/_Ato2015-2018/2017/Lei/L13415.htm. Acesso em: 15 jan. 2020.

BRASIL. Ministério da Educação. Secretaria de Educação Média e Tecnológica. Programa de melhoria e expansão do ensino médio projeto escola jovem. Brasília: MEC, 2000. Disponível em: http://portal.mec. gov.br/setec/arquivos/pdf/Escola\%20Jovem.pdf. Acesso em: 25 fev. 2020.

BRASIL. Instituto Nacional de Estudos e Pesquisas. Censo Escolar de 2018. Disponível em: http://portal. inep.gov.br/web/guest/censo-escolar. Acesso: 8 fev. 2020.

BRASIL. Lei № 13.005/2014. Aprova o Plano Nacional de Educação - PNE e dá outras providências. Disponível em: https://www2.camara.leg.br/legin/fed/lei/2014/lei-13005-25-junho-2014-778970-publicacaooriginal-144468-pl.html. Acesso em: 20 maio 2019.

CALDART, Roseli Salete. Por uma educação do campo: traços de uma identidade em construção. In: ARROYO, Miguel Gonzales; CALDART, Roseli Salete; MOLINA, Mônica Castagna (org.). Por uma educação do campo. 2. ed. Petrópolis, RJ: Vozes, 2004.

CARNOY, Martins. Educação, economia e estado: base e superestrutura, relações e mediações. Tradução Dagmar M. L. Zibas. São Paulo: Cortez; Autores Associados, 1986. 
CARVALHO, Marcio Bernardes de; SOARES, Neuzita de Paula; SALOMÉ, Josélia Schwanka. Reforma do Ensino Médio: a interferências dos organismos internacionais nas políticas educacionais brasileiras. In: CONGRESSO NACIONAL DE EDUCAÇÃO, 13., 2017. Curitiba. Anais [...]. Curitiba: UFPR, 2017. Disponível em: https://educere.bruc.com.br/arquivo/pdf2017/25103_13643.pdf. Acesso em: 20 mar. 2020

CELLARD, André. A análise documental. In: POUPART, Jean et al. A pesquisa qualitativa: enfoques epistemológicos e metodológicos. Tradução Ana Cristina Nasser. Petrópolis, RJ: Vozes, 2008. p. 295-316.

CURY, Carlos Roberto Jamil. O ensino médio no Brasil: histórico e perspectivas. Educação em Revista, n. 27, 1998. Disponível em: http://educacaoemrevistaufmg.com.br/edio-anterior/educacao-em-revista-no-27-ano-1998/. Acesso em: 8 mar. 2020.

DUARTE, Rita de Cássia; DERISSO, José Luís. A reforma neoliberal do ensino médio e a gradual descaracterização da escola. Germinal: Marxismo e Educação em Debate, Salvador, v. 9, n. 2, p. 132-141, set. 2017. Disponível em: https://portalseer.ufba.br/index.php/revistagerminal/article/view/21857. Acesso em: 20 jan. 2020.

FERREIRA, Benedito de J. Tecnologias da informação e comunicação na educação: avanço no processo de humanização ou fenômeno de alienação? Germinal: Marxismo e Educação em Debate, Salvador, v. 7, n. 1, p. 89-99, jun. 2015. Disponível em: https://www.google.com/search?q=uso+de+tecnologia+benedito+ferreira\&oq=uso+de+tecnologia+benedito+ferreira\&aqs=chrome..69i57.15320j0j8\&sourceid=chrome\&ie=UTF-8. Acesso em: $17 \mathrm{fev} .2020$.

FRIGOTTO, Gaudêncio. A produtividade da escola improdutiva: um (re)exame das relações entre educação e estrutura econômico-social capitalista. 9. ed. São Paulo: Cortez, 2010a.

FRIGOTTO, Gaudêncio. A educação e a crise do capitalismo real. 6. ed. São Paulo: Cortez, 2010b.

FRIGOTTO, Gaudêncio. O enfoque da dialética materialista histórica na pesquisa educacional. In: FAZENDA, Ivani (org.). Metodologia da pesquisa educacional. 11. ed. São Paulo: Cortez, 2008. p. 75-100.

HADDAD, Sérgio et al. Banco Mundial, OMC e FMI: o impacto nas políticas educacionais. São Paulo: Cortez, 2008.

KOSIK, Karel. Dialética do concreto. Tradução Cecília Novaes e Alderisco. 2. ed. Rio de Janeiro: Paz e Terra, 2011.

LOMBARDI, José Claudinei. Algumas questões sobre educação e ensino em Marx e Engels. Revista HISTEDBR On-line, Campinas, número especial, p. 347-366, abr. 2011. Disponível em: https://periodicos.sbu. unicamp.br. Acesso em: 3 ago. 2019.

MANACORDA. Mário Alighiero. Marx e a pedagogia moderna. Tradução Newton Ramos de Oliveira. 2. ed. Campinas, SP: Editora Alínea, 2010.

MARTINS, Lígia Márcia. O que ensinar? O patrimônio cultural humano como conteúdo de ensino e a formação da concepção de mundo no aluno. In: PASQUALINI, Juliana Campregher; AGUDO, Marcela de Moraes; TEIXEIRA, Lucas André (org.). Pedagogia histórico-crítica: legado e perspectivas. Uberlândia: Navegando Publicações, 2018.

MARX, Karl. Contribuição à crítica da economia política. Tradução Maria Helena Barreiro Alves. Revisão Carlos Roberto F. Nogueira. 2. ed. São Paulo: Martins Fontes, 1983.

MÉSZÁROS, István. A educação para além do capital. Tradução Isa Tavares. 2. ed. São Paulo: Boitempo, 2008.

PARÁ. Conselho Estadual de Educação. Resolução N. 202 de 25 de abril de 2017. Autoriza a implantação do Sistema Educacional Interativo - nos termos, limites e condições constantes da análise do parecer $n$ 은 205/2017-CE/PA, na Rede Estadual de ensino do Pará. 2017a. Disponível em: http://www.cee.pa.gov.br/ sites/default/files/doc10028920171030211720.pdf. Acesso em: 20. Jan. 2020.

PARÁ. Plano de implantação do Sistema Educacional Interativo SEI: Proposta de Ampliação do Ensino Médio Regular com Mediação Tecnológica. Seduc, 2017b. Disponível em: https://www2.mppa.mp.br/sistemas/gcsubsites/upload/37/Plano\%20de\%20Implementacao\%20do\%20SEl\%20-\%20SEDUC.PDF. Acesso em: 20 abr. 2019

PARÁ. Conselho Estadual de Educação. Parecer 205 de 06 de abril de 2017. Projeto de implantação, a partir do ano letivo de 2018, do Sistema Educacional Interativo - SEI - Ensino Médio presencial mediado por tecnologias. 2017c. Disponível em: https://docero.com.br/doc/8vvv8n. Acesso em: 25 jan. 2020.

ROSENTHAL, Mark. O método dialético marxista. São Paulo: Vitória, 1951.

SANTOS JÚNIOR, Claudio de Lira. A pedagogia histórico-crítica e o papel da escola e do professor: elementos para pensar a escola da transição. In: PASQUALINI, Juliana Campregher; AGUDO, Marcela de Moraes; TEIXEIRA, Lucas André (org.). Pedagogia histórico-crítica: legado e perspectivas. Uberlândia: Navegando Publicações, 2018. 


\section{\& Contexto}

SAVIANI, Dermeval. Escola e democracia: teorias da educação, curvatura da vara, onze teses sobre educação política. 36. ed. Campinas, SP: Autores Associados, 2003a. (Polêmicas do nosso tempo, v. 5).

SAVIANI, Dermeval. Pedagogia histórico-crítica: primeiras aproximações. 8. ed. revista e ampliada. Campinas, SP: Autores Associados, 2003b. (Educação contemporânea).

SAVIANI, Dermeval. As teorias da educação e o problema da marginalidade na América Latina. Caderno de Pesquisa, São Paulo, n. 42, p. 8-18, ago. 1982. Disponível em: http://publicacoes.fcc.org.br/ojs/index. php/cp/article/view/1546. Acesso em: 28 mar. 2020.

SAVIANI, Dermeval.; DUARTE, Newton. A formação humana na perspectiva histórico-ontológica. Revista Brasileira de Educação, v. 15 n. 45, set./dez. 2010. Disponível em: http://www.scielo.br/pdf/rbedu/ v15n45/02. Acesso em: 12 jan. 2020.

SEVERINO, Antônio Joaquim. Metodologia do trabalho científico. 23. ed. São Paulo: Cortez, 2007.

SILVA, Monica Ribeiro da. Currículo e competência: a formação administrativa. São Paulo: Cortez, 2008. 